\title{
Frequency of Cataract and its Association with Tobacco Use in Subjects of an Eye Camp
}

\author{
Saba Alkhairy, Farnaz Siddiqui, Mazhar-ul-Hassan, Arif Nayani
}

Pak J Ophthalmol 2019, Vol. 35, No. 2

See end of article for

authors affiliations

Correspondence to:

Dr. Saba Alkhairy

MBBS, FCPS, (OPHTH)

Assistant Professor DIMC,

DUHS

Email:

saba.alkhairy1@gmail.com
Purpose: To find the frequency of cataract and to study the relationship between cataract development and tobacco use.

Study Design: Cross sectional study.

Place and Duration of Study: Single day eye camp at Dow University Hospital Karachi in August 2016.

Material and Methods: All patients presenting to the camp were screened through standard eye examination including refraction and fundoscopy. After dilatation of pupil these patients were examined with a slit lamp by a consultant ophthalmologist for confirmation of the presence of cataract and its type. Participants were then questioned regarding the type of tobacco use and its duration and frequency with which it was consumed. Those patients with a history of tobacco consumption for more than ten years were included in the study.

Results: A total of 550 patients presented to the eye camp of which 120 $(21.81 \%)$ subjects were found to have a cataract. The mean age of the subjects was $58.02 \pm 8.3$ years. There were $67(55.8 \%)$ males and $53(44.2 \%)$ females. Among the patients diagnosed with cataract $89(74.2 \%)$ had no history of tobacco usage while $31(25.8 \%)$ gave a positive response regarding tobacco consumption. In nonsmokers the most common cataract was cortical where as in cigarette smokers it was nuclear $8(57.1 \%)$ and in users of smokeless tobacco it was posterior subcapsular $5(38.5 \%)$. There were no pseudophakic patients seen as almost all came from remote areas where there was lack of surgical facility.

Conclusion: Tobacco consumption has a strong association with cataract development. Cigarette Smoking as well as chewing smokeless tobacco should be curtailed or avoided altogether.

Keywords: Cataract, tobacco, visual acuity.

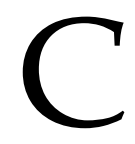
ataract is one of the major causes of blindness worldwide accounting for nearly half of all blindness globally ${ }^{1}$. According to the World Health Organization (WHO), nearly 20 million people throughout the world suffer from reduced vision, of $3 / 60$ or less, due to cataract. These figures are predicted to increase to 40 million by the next year. Although there are now various surgical procedures for extraction of cataract and hence to improve vision, many people continue to have poor vision from cataracts due to lack of awareness, poor access to health care and operative facilities and high surgical expense $^{2}$. Epidemiologic studies imply that etiology of cataract is due to various factors and that their occurrence is related to increase in age. One particular factor suggested to be the cause of cataract 
development is injury to the lens by oxygen free radicles $^{3}$. Raw tobacco products and tobacco smoke both contain several materials, including nicotine, free radicals, and carbon monoxide, which can enhance the injury caused by oxidation and have a significant role in the development of cataract ${ }^{4,5}$.

Tobacco use has emerged as a serious health challenge in Pakistan that now stands among the top four countries of the world with rapid increase in tobacco market ${ }^{6}$. The various forms used are chewed, sucked, or applied to teeth or gums. Smokeless tobacco is sold as packets of strands and is used alone or along with betel leaf, areca nut and lime.

As the country is currently suffering from epidemic of Tobacco addiction therefore the rationale of the study was to study the effects of Tobacco use in general and smoking in particular so as to increase public awareness about its potential health hazards. Strict laws should be implemented to actively ban advertisement and promotion of tobacco and tobacco related products. The objective of this study was to study the frequency of cataract and to determine the association between tobacco consumption and cataract development.

\section{MATERIAL AND METHODS}

A total of 550 adult patients visited an eye camp which was held on a single day in August 2016. All these patients underwent visual acuity assessment using a Topcon KR-800PA Auto Refractor followed by a subjective test with Snellen chart at 6 meters with standard illumination by two qualified optometrists. Illiterate subjects were assessed using the $\mathrm{E}$ chart while literate subjects were tested using the standard letters. Individuals including both males and females and those aged more than 40 were analyzed further. They were dilated with tropicamide $1 \%$ eye drops instilled every 10 minutes for 30 minutes. After full dilatation the cataract if detected was graded with lens opacities classification system. Cataract was categorized as any LOCS III grading of $\geq 2$ in either eye. Cortical, nuclear, and posterior sub capsular cataracts (PSC) were defined as LOCS III $\geq 2$. Also detailed examination was done of the cornea, the anterior segment, disc, macula and remaining retina along with gonioscopy and tonometry to rule out other causes of decreased vision. They were then questioned in detail by a single person as most were illiterate and were not able to answer the questionnaire themselves. The subjects were then divided into two groups: those who consumed tobacco in any form and those who had no history of smoking, chewing tobacco or its utilization. Those who were smokers or consumed tobacco in any form were further inquired about the kind of tobacco (cigarette or smokeless tobacco) use if any and the duration of usage in terms of quantity and years. All the data gathered was entered into questionnaires and was analyzed statistically using IBM SPSS version 21 .

The results were presented as Mean \pm SD for Age, frequency and percentages for gender, tobacco use and type of cataract. Statistical association was calculated between cataract type with gender and tobacco use using chi-square test. A p-value of 0.05 or less was considered statistically significant.

\section{RESULTS}

Amongst the total number of 550 patients presenting to the OPD those who fulfilled the criteria were found to be 120 subjects, who were analyzed. Table 01 describes the descriptive statistics of all respondents. Mean \pm standard deviation of age (58.02 \pm 8.3 years). Frequency and percentages of males were 67 (55.8\%) and females were 53 (44.2\%). Persons who did not use any tobacco were higher i.e. $89(74.2 \%)$. For Cataract type PSC was found to be $36(30 \%)$ followed by cortical 35 (29.2\%) and others respectively.

Table 1: Descriptive Statistics of respondents.

\begin{tabular}{|ll|}
\hline \multicolumn{1}{|c|}{ Characteristics } & $\mathbf{N}=\mathbf{1 2 0}(\mathbf{0})$ \\
\hline $\begin{array}{l}\text { Age years (Mean } \pm \text { SD) } \\
\text { Gender }\end{array}$ & $58.02 \pm 8.3$ \\
Male & $67(55.8 \%)$ \\
Female & $53(44.2 \%)$ \\
Tobacco Use & \\
Nil & $89(74.2 \%)$ \\
Betel Nuts & $13(10.8 \%)$ \\
Cigarettes & $14(11.7 \%)$ \\
Others & $4(3.3 \%)$ \\
Cataract type & $36(30 \%)$ \\
PSC & $35(29.2 \%)$ \\
Cortical & $24(20 \%)$ \\
Nuclear Cataract & $12(10 \%)$ \\
Cortical + Nuclear & $13(10.8 \%)$ \\
Cortical + PSC &
\end{tabular}

Table 2 describes the association of cataract type with gender and tobacco use. Amongst the 67 male patients the occurrence of cortical cataract was higher $29.9 \%$ where proportions of cortical with nuclear were 
Table 2: Relationship of Cataract with Gender and Tobacco use.

\begin{tabular}{|c|c|c|c|c|c|c|c|}
\hline \multirow[b]{2}{*}{ Characteristics } & \multicolumn{7}{|c|}{ Cataract Type } \\
\hline & $\begin{array}{c}\text { PSC } \\
(n=36)\end{array}$ & $\begin{array}{c}\text { Cortical } \\
(n=35)\end{array}$ & $\begin{array}{c}\text { Nuclear } \\
\text { Cataract } \\
(n=24)\end{array}$ & $\begin{array}{c}\text { Cortical + } \\
\text { Nuclear } \\
(n=12)\end{array}$ & $\begin{array}{c}\text { Cortical + } \\
\text { PSC } \\
(n=13)\end{array}$ & Total & P-Value \\
\hline \multicolumn{8}{|l|}{ Gender } \\
\hline Male & $19(28.4 \%)$ & $20(29.9 \%)$ & $13(19.4 \%)$ & $5(7.5 \%)$ & $10(14.9 \%)$ & 67 & \multirow{2}{*}{0.8} \\
\hline Female & $17(32.1 \%)$ & $15(28.3 \%)$ & $11(20.8 \%)$ & $7(13.2 \%)$ & $3(5.7 \%)$ & 53 & \\
\hline \multicolumn{8}{|l|}{ Tobacco use } \\
\hline Nil & $25(28.1 \%)$ & $28(31.5 \%)$ & $12(13.5 \%)$ & $12(13.5 \%)$ & $12(13.5 \%)$ & 89 & \multirow{4}{*}{$0.02 * \sim$} \\
\hline Betel Nuts & $5(38.5 \%)$ & $3(23.1 \%)$ & $4(30.8 \%)$ & $0(0.0 \%)$ & $1(7.7 \%)$ & 13 & \\
\hline Cigarettes & $4(28.6 \%)$ & $2(14.3 \%)$ & $8(57.1 \%)$ & $0(0.0 \%)$ & $0(0.0 \%)$ & 14 & \\
\hline Others & $2(50.0 \%)$ & $2(50.0 \%)$ & $0(0.0 \%)$ & $0(0.0 \%)$ & $0(0.0 \%)$ & 4 & \\
\hline \multicolumn{8}{|l|}{ Significant at 5\% } \\
\hline$\sim$ Cells proportio & & & & & & & \\
\hline
\end{tabular}

very less i.e. $7.5 \%$. In females out of 53,17 (32.1\%) had PSC and only $5.7 \%$ had cortical with PSC. There was no significant association found for gender $(\mathrm{P}$-value $=$ 0.8 ). A significant association was found due to the tobacco and occurrence of different cataract types (Pvalue $=0.02<0.05)$.

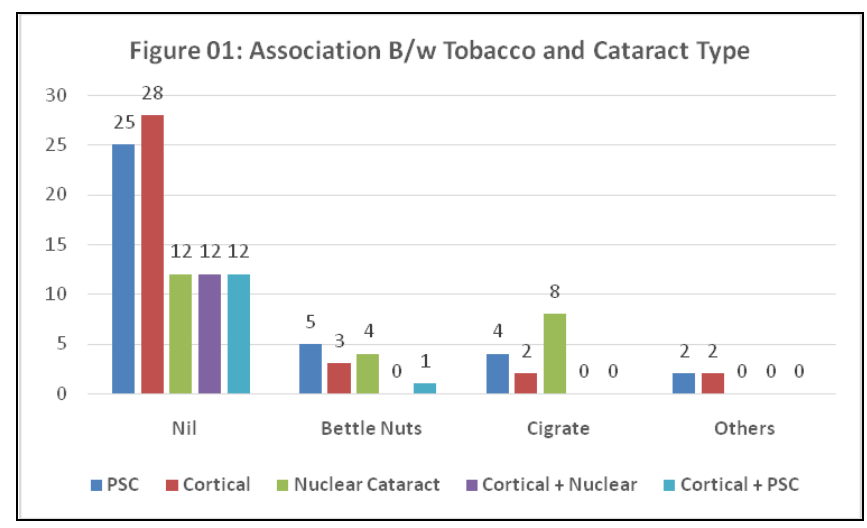

Fig 1: Association between Tobacco and cataract Type.

\section{DISCUSSION}

Of all the causes leading to visual impairment all over the world, cataract is at the top of the list ${ }^{7}$. In a study conducted on elderly patients living in Taiwan the three most common causes of visual impairment were found to be cataract $(41.7 \%)$, seconded by myopic macular degeneration (12.5\%) and then age-related macular degeneration $(10.4 \%)^{8}$. In another study done in an elderly home in South India the most common causes of visual impairment were due to avoidable causes including cataract $(57.1 \%)$ and uncorrected refractive errors $(26.4 \%)^{9}$. A global data on visual impairment concluded the number of people with visual impairment worldwide in 2002 was more than 161 million and among them cataract remained the most important and leading cause of visual disability ${ }^{10}$.

Smoking causes damage to the lens through oxidation by reducing the inherent antioxidative ability of the lens by depleting substances as such as vitamin $C$, vitamin $E$, and $\beta$-carotene ${ }^{11.12}$. Another reason is that certain substances of tobacco contain heavy metals, such as cadmium, lead, and copper, which are directly harmful to lens and can also lead to formation of cataract ${ }^{13,14}$.

In Southeast Asia, tobacco is consumed in various ways, including cigarettes or bides (dried tobacco rolled in paper or leaf), chewing khaini (tobacco with slaked lime and aromatic spices), sutra (dried tobacco leaves for chewing), or pan masala (tobacco with betel leaf), sucking gutka (mixture of tobacco and molasses available in small sachets), and inhaling of naswar (nasal inhalation of tobacco powder) ${ }^{15}$. In our study we analyzed a total of 120 subjects of whom 89 were nonsmokers and 31 were smokers. Cigarette smoking was the most common form of tobacco use observed in 14 subjects $(11.7 \%)$, followed by betel nut chewing with grounded tobacco which was noted to be 13 $(10.8 \%)$ subjects, while a category of others included 4 $(3.3 \%)$ subjects. The others represented a category who consumed tobacco in various smokeless forms of tobacco as mentioned above. The most common type of cataract seen in nonsmokers was cortical cataract while in those individuals who were cigarette smokers 
the most common type was nuclear cataract and in users of smokeless tobacco such as betel nut users it was posterior subcapsular cataract. This is consistent with other studies such as a Meta analysis done by Juan le ET al ${ }^{16}$ and various other studies conducted in different countries of the world such as Singapore, India and Australia respectively ${ }^{17-20}$.

In our study there was no significant association found in gender $p=0.8$. Overall in all of 120 subjects cataract was found more in males as opposed to females but that is because of the increased number of male subjects presenting to the hospital. The most common cataract found in females was posterior subcapsular which was seen in 17 (32.1\%) while the most common cataract found in males was cortical that was seen in 20 (29.9\%). This conflicts with studies which have concluded that most common cataract found in women is nuclear conducted in United States and Australia ${ }^{21.22 .}$

The prevalence of cataract seen in our study was estimated to be $21.81 \%$.This is almost similar to another study conducted known as the Beaver eye dam study which estimated an incidence of $21 \% 23$. However the prevalence was higher in other studies such as Zhang Js who estimated the prevalence of cataract in China to be $35 \%{ }^{24}$. In another study done in Singapore the prevalence reported was 34.7\% (95\% CI, $31.5,38.0)^{25}$.

Limitations of the study are that prevalence of age related cataracts alone is difficult to determine as there are multifactorial causes of Cataract formation such as increasing age, trauma, use of steroids etc. Also to study association of tobacco smoking with cataract a larger sample size is recommended. People were vague in their history regarding the mode of tobacco consumption and were especially hesitant to discuss the duration of its usage because of social stigma. Furthermore as most patients selected for final evaluation were more than 40 years old in which age related cataracts are more common it adds more confusion to build any definite association.

\section{CONCLUSION}

The prevalence of cataract seen in our study was estimated to be $21.81 \%$. There was no significant association found for gender and cataract development. A significant association was found between tobacco consumption and occurrence of different cataract types of which the most common type of cataract seen was posterior subcapsular.

\section{Author's Affiliation}

Dr. Saba Alkhairy

MBBS, FCPS, (OPHTH)

Assistant Professor DIMC, DUHS

Dr. Farnaz Siddiqui

MBBS, FCPS, (OPHTH)

Assistant Professor DIMC, DUHS

Dr. Mazhar UL Hassan

MBBS, MCPS, FCPS, (OPHTH)

Professor and Head of department DIMC, DUHS

Dr. Arif Nayani

MBBS, Medical officer

DIMC, DUHS

\section{Author's Contribution}

Dr. Saba Alkhairy

Data collection, analysis and manuscript writing.

Dr. Farnaz Siddiqui

Data collection and analysis.

Dr. Mazhar UL Hassan

Study design and critical analysis.

Dr. Arif Nayani

Data collection and literature review.

\section{Conflict of Interest}

The authors have no conflict of interest to declare.

\section{REFERENCES}

1. Bourne R, Stevens GA, White RA, et al. Causes of vision loss worldwide. Lancet Global Health, 2013; 1: e339-e349.

2. Lindfield R, Vishwanath $K$, Ngounou F, Khanna RC. The challenges in improving outcome of cataract surgery in low and middle income countries. Indian J Ophthalmol. 2012; 60: 464-469.

3. Vinson JA. Oxidative stress in cataract. Pathophysiology, 2006 Aug; 13 (3): 151-62.

4. Prakash C G, Cecily S R. Smokeless tobacco and health in India and South Asia. Respirology, 2003; 8: 419-431.

5. Fletcher AE. Free radicals, antioxidants and eye disease: evidence from epidemiological studies on cataract and age-related macular degeneration. Ophthalmic Res. 2010; 44 (3): 191-193.

6. Gilani SI, Leon DA. Prevalence and sociodemographic determinants of tobacco use among adults in Pakistan: findings of a nationwide survey conducted in 2012. Popul Health Metr. 2013; 11: 16.

7. Brian G, Taylor HR. Cataract blindness; challenges for the $21^{\text {st }}$ century. Bull World Health Org. 2001; 79: 249256. 
8. Hsu WM Cheng CY Liu JH Tsai SY Chou P. Prevalence and causes of visual impairment in an elderly Chinese population in Taiwan: the Shihpai Eye Study. Ophthalmology, 2004; 111: 62-69.

9. Dandona L, Dandona $\mathbf{R}$, Srinivas $\mathbf{M}$, et al. Blindness in the Indian state of Andhra Pradesh. Invest Ophthalmol Vis Sci. 2001; 42 (5): 908-916.

10. Resnikoff S, Pascolini D, Etya'ale D, et al. Global data on visual impairment in the year 2002. Bull World Health Organ. 2004; 82 (11): 844-851.

11. Valero MP, Fletcher AE, De Stawola BL, Vioque J, Alepuz VC. Vitamin C is associated with reduced risk of cataract in a Mediterranean population. J Nutr. 2002; 132 (6): 1299-306.

12. Wei L, Liang G, Cai C, Lv J. Association of vitamin C with the risk of age-related cataract: a meta-analysis. Acta Ophthalmol. 2016; 94: 170-176.

13. Langford-Smith A, Tilakaratna V, Lythgoe PR, Clark SJ, Bishop PN, Day AJ. Age and Smoking Related Changes in Metal Ion Levels in Human Lens: Implications for Cataract Formation. PLoS One. 2016 Jan 21;11(1):e0147576.

14. Nirmalan $\mathbf{P} \mathbf{K}$, Robin A L, Katz J, Tielsch JM, Thulasiraj RD, Krishnadas R, Ramakrishnan R. Risk factors for age related cataract in a rural population of Southern India: the Aravind comprehensive eye study. Br J Ophthalmol. 2004; 88: 989-994.

15. Jarvis MJ, Wardle J. Social patterning of individual health behaviours: the case of cigarette smoking. Edited by Marmot M, Wilkinson RG. Oxford: Oxford University Press; 2005.

16. Ye j, He J, Wang C, Wu H, Shi X, Zhang H, Xie J, Lee SY. Smoking and risk of age-related cataract: A metaanalysis. Investigative Ophthalmology and Visual Science, 2012; 53: 3885-3895.

17. Foster PJ, Wong TY, Machin D, et al. Risk factors for nuclear, cortical and posterior subcapsular cataracts in the Chinese population of Singapore: the Tanjong Pagar survey. Br J Ophthalmol. 2003; 87: 1112-20.

18. Nirmalan PK, Robin AL, Katz J, et al. Risk factors for age related cataract in a rural population of Southern India: the Aravind comprehensive eye study.Br J Ophthalmol. 2004; 88: 989-94.

19. Krishnaiah S, Vilas K, Shamanna BR, et al. Smoking and its association with cataract: results of the Andhra Pradesh Eye Disease Study from India. Invest Ophthalmol Vis Sci. 2005; 46: 58-65.

20. Tan JS Wang JJ Younan C Cumming RG Rochtchina E. Smoking Mitchell $\mathrm{P}$ and the long-term incidence of cataract: the Blue Mountains Eye Study. Ophthalmic Epidemiol. 2008; 15: 155-161.

21. Congdon NO, Colmain B, Klaver CC et al. Eye Diseases Prevalence Research Group, Causes and prevalence of visual impairment among adults in the United States. Arch Ophthalmol. 2004; 122 (4): 477-485.

22. Delcourt C, CristolJ P, Tessier F. Leger CL. Michel F, Papoz L. POLA Study Group. Risk factors for cortical, nuclear, and posterior subcapsular cataracts: the POLA study. Am J Epidemiol. 2000; 151 (5): 497-504.

23. Klein BEK, Klein R, Linton KLP, Magli YL, Neider MW. Assessment of cataracts from photographs in the Beaver Dam Eye Study. Ophthalmology, 1990; 97: 142833.

24. Zhang JS, Xu L, Wang YX, You QS, Wang JD, Jonas JB. Five-year incidence of age-related cataract and cataract surgery in the adult population of greater Beijing: the Beijing Eye Study. Ophthalmology, 2011; 118: 711-718.

25. Seah SKL, Wong TY, Foster PJ, Ng TP, Johnson GJ. Prevalence of lens opacity in Chinese residents of Singapore: the Tanjong Pagar survey. Ophthalmology, 2002; 109: 2058-2064. 